\title{
AITC induces MRP1 expression by protecting against CS/CSE-mediated DJ-1 protein degradation via activation of the DJ-1/Nrf2 axis
}

\author{
Lingling $\mathrm{Xu}^{1, \#}$, Jie Wu ${ }^{1,2, \#}$, Nini $^{\mathrm{Li}}{ }^{1}$, Chengjun Jiang ${ }^{1}$, Yan Guo ${ }^{1}$, Peng $\mathrm{Cao}^{3, *}$, and Dianlei Wang ${ }^{1,4, *}$ \\ ${ }^{1}$ School of Pharmacy, Anhui University of Chinese Medicine, Hefei, Anhui 230012, ${ }^{2}$ Department of Pharmacy, Lu'an People's Hospital Affiliated to \\ Anhui Medical University, Lu'an, Anhui 237016, ${ }^{3}$ Laboratory of Cellular and Molecular Biology, Jiangsu Academy of Chinese Medicine, Nanjing, Jiangsu \\ $210028,{ }^{4}$ Anhui Province Key Laboratory of Research \& Development of Chinese Medicine, Hefei 230012, P.R. China
}

\author{
ARTICLE INFO \\ Received June 2, 2020 \\ Revised July 9, 2020 \\ Accepted July 20, 2020 \\ *Correspondence \\ Dianlei Wang \\ E-mail: dlwang@ahtcm.edu.cn \\ Peng Cao \\ E-mail: pcao79@yahoo.com
}

\section{Key Words}

Allyl isothiocyanate

Chronic obstructive pulmonary disease

DJ-1/Nrf2

Multidrug resistance-associated protein 1

\#These authors contributed equally to this work.

\begin{abstract}
The present study aimed to examine the effect of allyl isothiocyanate (AITC) on chronic obstructive pulmonary disease and to investigate whether upregulation of multidrug resistance-associated protein 1 (MRP1) associated with the activation of the PARK7 (DJ-1)/nuclear factor erythroid 2-related factor 2 (Nrf2) axis. Lung function indexes and histopathological changes in mice were assessed by lung function detection and H\&E staining. The expression levels of Nrf2, MRP1, heme oxygenase-1 (HO-1), and DJ-1 were determined by immunohistochemistry, Western blotting and reverse transcription-quantitative polymerase chain reaction. Next, the expression of DJ-1 in human bronchial epithelial (16HBE) cells was silenced by siRNA, and the effect of DJ-1 expression level on cigarette smoke extract (CSE)-stimulated protein degradation and AITC-induced protein expression was examined. The expression of DJ-1, Nrf2, HO-1, and MRP1 was significantly decreased in the wild type model group, while the expression of each protein was significantly increased after administration of AITC. Silencing the expression of DJ-1 in 16HBE cells accelerated CSE-induced protein degradation, and significantly attenuated the AITC-induced mRNA and protein expression of Nrf2 and MRP1. The present study describes a novel mechanism by which AITC induces MRP1 expression by protecting against CS/CSEmediated DJ-1 protein degradation via activation of the DJ-1/Nrf2 axis.
\end{abstract}

\section{INTRODUCTION}

Smoking is the main reason for the onset of chronic obstructive pulmonary disease (COPD). Cigarette smoke (CS) contains a variety of reactive oxygen species (ROS), such as superoxide and hydrogen peroxide. Excessive ROS generation leads to oxidative stress (OS), which drives the progression of pathophysiological events integral to the development of COPD, such as inflammatory reactions, mucus hypersecretion, airway remodeling, and pulmonary function impairment $[1,2]$. As an amphiphilic organic anion transporter, multidrug resistance-associated pro- tein 1 (MRP1) mainly mediates the excretion of exogenous toxic substances and the transmembrane transport of endogenous inflammatory factors [3]. MRP1 has become a focus for COPD therapeutic interventions due to its beneficial role in protecting the lung from OS injury and toxic damage. Previous studies have shown that MRP1 is highly expressed in control human lung tissue, whereas it is decreased in patients with COPD [4]. In a previous study, our group also confirmed that the level of MRP1 was significantly downregulated in bronchial epithelial cells of rats with COPD, and such decrease could lead to further deterioration of lung function [5]. Previous studies have shown that drugs can

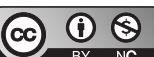

This is an Open Access article distributed under the terms of the Creative Commons Attribution Non-Commercial License, which permits unrestricted non-commercial use, distribution, and reproduction in any medium, provided the original work is properly cited. Copyright @ Korean J Physiol Pharmacol, pISSN 1226-4512, elSSN 2093-3827
Author contributions: L.L.X., J.W., D.L.W., N.N.L., and C.J.J., Y.G., P.C. designed the experiments. L.L.X. and J.W. performed in vivo experiments and analyzed the corresponding results. L.L.X. and J.W., N.N.L. performed in vitro experiments and analyzed the results. J.W. wrote the paper with D.L.W. and P.C. 
affect the treatment of COPD by upregulating the expression and function of MRP1 [6].

Allyl isothiocyanate (AITC) is one of the common natural Isothiocyanates (ITCs), which are mainly found in Brassicaceae vegetables [7]. Although the structures of ITCs vary, they are similar in terms of prevention of irritant and effects on diseases. AITC is a powerful inducer of phase II detoxification enzymes [810], and nuclear factor erythroid 2-related factor 2 (Nrf2) plays a major role in the formation and expression of phase II enzymes, including heme oxygenase-1 (HO-1) and NADPH quinone oxidoreductase-1 [11]. A previous study suggested that Nrf2 could be an essential target for the treatment of COPD [12]. In recent years, increasing evidence has shown that Nrf2 activation is dependent on its positive regulator PARK7 (DJ-1), a protein encoded by the PARK7 gene. At the level of electrical or chemical stimulation, DJ-1 prevents Nrf2 from recombining with Kelch-like ECHassociated protein 1 and reduces the subsequent ubiquitination of Nrf2, which is important for maintaining the stability of the antioxidant defense system $[13,14]$. Several studies have found that the Nrf2-antioxidant response element (ARE) signaling pathway participates in the regulation of the expression of phase II enzymes, and regulates the expression of transporter MRPs [15]. AITC has been demonstrated to be a highly effective inducer of phase II enzymes, and can also alter the protein expression of MRP1. Our previous study found that AITC can increase the function and expression of MRP1 in control human bronchial epithelial (16HBE) cells in a time and dose-dependent manner [16]. However, the mechanisms by which AITC upregulates the expression of MRP1 remain to be fully elucidated. Thus far, there are no reports on the ability of AITC to enhance the expression and activity of MRP1 regulated by the DJ-1/Nrf2 axis under COPD conditions. The present study combined in vivo and in vitro experiments to illustrate that AITC may provide a therapeutic strategy for COPD through activation of the DJ-1/Nrf2 axis and upregulation expression of MRP1.

\section{METHODS}

\section{Reagents}

AITC was purchased from Anhui Haibei Import and Export Co., Ltd. (Hefei, Anhui, China). N-acetylcysteine (NAC) was purchased from Shanghai Huicheng Biotechnology Co., Ltd. (Shanghai, China). Anti-DJ-1 (ab76008), anti-MRP1 (ab260038), antiNrf2 (ab62352), anti-HO-1 (ab52947), and anti-GAPDH (ab8245) antibodies were purchased from Abcam (Cambridge, UK). Goat anti-rabbit IgG (ZB-2301) was obtained from the Beijing Zhongshan Jinqiao Biotechnology Co., Ltd. (Beijing, China). The bicinchoninic acid protein assay kit was purchased from Beijing Pleilai Gene Technology Co., Ltd. (Beijing, China). Lipofectamine 2000 and TRIzol reagent was purchased from Invitrogen (Carlsbad,
CA, USA). High-Capacity cDNA Archive kit was purchased from Fermentas (Thermo Fisher Scientific, Inc., Waltham, MA, USA).

\section{Animal model}

All the animal procedures involving rats and the experimental protocols described in the present study were approved by the Anhui University of Chinese Medicine Animal Care Committee and Use Committee (Anhui, China). C57BL/JNju wild type (WT) mice were purchased from the Biomedical Research Institute of Nanjing University (order no. SCXK [SU]201701627). Nrf2 knockout $\left(\mathrm{Nrf2}^{--}\right.$) mice, which were provided by Jiangsu Academy of Chinese Medicine, were originally purchased from Johns Hopkins University (Baltimore, MD, USA) and expanded at the Animal Center of Anhui University of Chinese Medicine. WT mice and $\mathrm{Nrf2}^{-1}$ mice were subjected for 5 days per week (4 times per day, $1 \mathrm{~h}$ per 1 time) during 3 months to the smoke of cigarettes in a homemade cigarette smoke exposure system $(100 \times$ $100 \times 100 \mathrm{~cm}^{3}$ ), which had a $2-\mathrm{cm}$ diameter vent hole in the top to maintain the cylinder pressure for smoke inhalation (tar, $19 \mathrm{mg}$; nicotine, $1.2 \mathrm{mg}$, The Red Tricyclic Cigarettes; Chuzhou cigarette factory, Chuzhou, Anhui, China) [17].

\section{Administration}

A total of $40 \mathrm{Nrf2}^{-1-}$ mice were randomly divided into four groups: Control group, COPD model group, AITC group and NAC positive group, while $40 \mathrm{WT}$ mice were also randomly assigned to the above four groups ( $\mathrm{n}=10$ per group). The dosing scheme was as follows: i) Control group, $0.5 \%$ sodium carboxymethyl cellulose was administered twice a day; ii) COPD model group, dosing consistent with the control group; iii) AITC group, AITC configured into $0.4 \mathrm{mg} / \mathrm{ml}, 1 \mathrm{ml} / 10 \mathrm{~g}$ volume of administration $(20 \mathrm{mg} / \mathrm{kg})$, twice a day; and iv) NAC positive group, NAC configured to $8.0 \mathrm{mg} / \mathrm{ml}, 1 \mathrm{ml} / 10 \mathrm{~g}$ volume of administration (800 $\mathrm{mg} / \mathrm{kg}$ ), twice a day. Intragastric administration continued for 15 days. AITC and NAC in the pharmacological experiments and our pre-experimental results served to determine the intragastric dose $[18,19]$.

\section{Determination of lung function A catheter is inserted into the trachea of the body}

After 15 days of intragastric administration, the mice in each group were anesthetized with $20 \%$ urethane $(1,000 \mathrm{mg} / \mathrm{kg})$, and the catheter was inserted into the trachea. The mice were placed in a closed body scanning chamber within a small animal ventilator, and their lung function was measured with the AniRes2005 animal lung function system. The parameters were recorded by software automatically including forced expiratory flows at 0.3 sec/forced vital capacity (FEV0.3/FVC\%), forced expiratory flows at $0.1 \mathrm{sec}$, peak expiratory flow (PEF), forced expiratory flow 
between $25 \%$ and $75 \%$ of forced vital capacity (FEF25-75) and Cldyn (Cdyn).

\section{Histopathology and immunohistochemistry}

For histopathology, 4- $\mu$ m-thick sections were stained with $\mathrm{H} \& \mathrm{E}$ for pathological evaluation. The destructive index (DI) was used to evaluate changes in the pathological morphology of alveoli. Three lung tissue sections were selected from each group, and each section was selected from at least 20 airways at $\times 100$ magnification. Normal alveolar was marked as N, while damaged alveolar was marked as D. DI was calculated according to the following formula: $\mathrm{DI}=\mathrm{D} /(\mathrm{D}+\mathrm{N}) \times 100 \%$. Airway inflammation scores were based on the research by Gueders et al. [20]. Three lung tissue sections were selected from each mouse, and each section was selected from at least 20 airways at $\times 200$ magnification. The scores were used to determine the degree of inflammatory cell infiltration around the airway. For immunohistochemistry, following incubation with $3 \%$ hydrogen peroxide for $30 \mathrm{~min}$ to inactivate endogenous peroxidase, 4 - $\mu \mathrm{m}$-thick sections were blocked with goat serum (Beijing Zhongshan Jinqiao Biological Technology Co., Ltd.) to prevent the non-specific binding of antibodies. Next, lung tissue sections were incubated with antiDJ-1 (1:500), anti-MRP1 (1:500) and anti-Nrf2 (1:250) monoclonal antibodies at $37^{\circ} \mathrm{C}$ for $30 \mathrm{~min}$ then kept at $4^{\circ} \mathrm{C}$ overnight. Once the section was washed, a secondary antibody (ab150077, Abcam; 1:100) was added and incubated for $20 \mathrm{~min}$ at room temperature. The sections were developed using a diaminobenzidine solution according to the manufacturer's instructions. Finally, the sections were counterstained with methyl green or hematoxylin and the images were captured at $\times 400$ magnification using a light microscope.

\section{Western blotting}

Cells or lung tissues were lysed using a mixture of RIPA 2000 and a protease inhibitor (RIPA:PMSF, 99:1). The supernatant was obtained by centrifugation $\left(12,000 \mathrm{~g}, 4^{\circ} \mathrm{C}, 10 \mathrm{~min}\right)$, mixed with loading buffer (4:1, Fermentas; Thermo Fisher Scientific, Inc.), heated in boiling water for $10 \mathrm{~min}$, and stored in $-20^{\circ} \mathrm{C}$. Protein samples were subjected to $6 \%-12 \%$ SDS-PAGE and transferred to a nitrocellulose membrane (NC). The NC membrane was then incubated with $5 \%$ skimmed milk powder for $2 \mathrm{~h}$, followed by incubated with the primary antibody, including anti-DJ-1 (1:1,000), anti-MRP1 (1:500), anti-Nrf2 (1:1,000), anti-HO-1 (1:2,000), and anti-GAPDH $(1: 2,000)$ antibodies. The next day, membranes were incubated with HRP-conjugated secondary antibodies (1:5,000) for $2 \mathrm{~h}$ at room temperature. Primary antibodies diluted with primary antibody dilution (Beyotime Institute of Biotechnology, Shanghai, China), while secondary antibodies were diluted with $5 \%$ nonfat milk. Finally, protein signals were visualized using ECL (Pierce; Thermo Fisher Scientific, Inc.) and a gel imager sys- tem. GAPDH was used as the relative quantitative internal reference. Protein gray values were analyzed with Image J2x software (National Institutes of Health, Bethesda, MD, USA).

\section{Cell line and culture}

The human bronchial epithelial cell line 16HBE was purchased from Zishi Biological Technology Company (Shanghai, China), and grown in Dulbecco's modified Eagle's medium (DMEM; HyClone; GE Healthcare Life Sciences, Logan, UT, USA) supplemented with $10 \%$ fetal bovine serum (Gibco, Carlsbad, CA, USA), and the cells were incubated at $37^{\circ} \mathrm{C}$ in a humidified atmosphere with $5 \% \mathrm{CO}_{2}$. In certain experiments, the cells were incubated with cigarette smoke extract (CSE) and AITC diluent. CS was continuously pumped through a self-made vacuum device, and the smoke of one cigarette was dissolved in $5 \mathrm{ml}$ DMEM. Within $30 \mathrm{~min}, \mathrm{CSE}$ was adjusted to $\mathrm{pH} 7.4$ and sterilized through a 0.22 $\mu \mathrm{m}$ filter. The concentration of CSE prepared according to the above method was regarded as $100 \%$ in this study. Subsequently, the toxicity of CSE to $16 \mathrm{HBE}$ cells was detected by MTT assay, and the experimental final stimulation concentration was determined. The incubation time $(24 \mathrm{~h})$ and concentration range (0-40 $\mu \mathrm{M})$ of AITC were selected based on a previously described [16].

\section{Transfection}

DJ-1 small interference RNA (siRNA) and negative control siRNA were designed and synthesized by Shanghai GenePharma Co., Ltd. (Shanghai, China). DJ-1 primer sequences were as follows: Forward, 5' -GACGGCCUGAUUCUUACAATT-3' and reverse, 5' -UUGUAAGAAUCAGGCCGUCTT-3'. siRNA was transfected into 16HBE cells using Lipofectamine 2000.

\section{Reverse transcription-quantitative polymerase chain reaction ( $R T-q P C R)$}

Total RNA was extracted from cells using TRIzol reagent. cDNA was generated using the High-Capacity cDNA Archive kit according to the manufacturer's instructions. RT-qPCR was performed with the SYBR Green Master Mix system (Applied Biosystems; Thermo Fisher Scientific, Inc.) and conducted in an ABI 7500 real-time PCR machine (Applied Biosystems; Thermo Fisher Scientific, Inc.). The primer sequences were as follows: For MRP1, forward, 5'-AGTTCTGCGGTGCTGTTGTG-3' and reverse, 5'-TTCGCTGAGTTCCTGCGTAC-3'; for Nrf2, forward, 5'-CACGGTCCACAGCTCATCAT-3' and reverse, 5'-CAAATCCATGTCCTGCTGGG-3'; for HO-1, forward, 5'-ACTGCGTTCCTGCTCAACAT-3' and reverse, 5'-GGGGCAGAATCTTGCACTTT-3'; for DJ-1, forward, 5'-GGTGAGTGGTACCCAACGG-3' and reverse, 5'-CCTTAATCCCAGCTCGCCTC-3'; and for the housekeeping gene GAPDH, forward, 5'-CTTCTTTTGCGTCGCCAGCC-3' and re- 
verse, 5'-GCCCAATACGACCAAATCCGT-3'. For data analysis, the comparative $2^{-\triangle \triangle C T}$ method was used [21]. The results were the average relative mRNA expression of the different genes normalized to GAPDH.

\section{Statistical analysis}

Data are presented as the mean \pm standard deviation. All samples were tested to ascertain if they followed a normal distribution. Student's t-test and one-way analysis of variance followed by a post-hoc conservative Tukey's test were used to calculate significant differences. Statistical analyses were performed with SPSS 17.0.1 (SPSS Inc., Chicago, IL, USA). $\mathrm{p}<0.05$ was considered to indicate a statistically significant difference.

\section{RESULTS}

\section{Association between Nrf2 and pathogenesis of CS- induced COPD}

In order to investigate the association between Nrf2 and pathogenesis of CS-induced COPD, $\mathrm{Nrf}^{-/}$and WT mice were exposed to CS. As shown in Table 1, compared with those of WT control group, FEV0.3/FVC\%, FEV0.1, PEF, FEF25-75, and Cdyn were significantly lower in the WT and $\mathrm{Nrf}^{-1}$ model groups $(\mathrm{p}<0.05)$, which is consistent with the pathological features of chronic bronchitis and obstructive emphysema. Compared with those in the WT model group, the changes in the above indicators were more obvious in the $\mathrm{Nrf}^{-1}$ model group $(\mathrm{p}<0.05)$. The H\&E staining results are shown in Fig. 1. Alveolar structure damage and inflammatory infiltration were observed in CS-induced WT mice, which were more serious in $\mathrm{Nrf}_{2}^{-/}$mice. These results revealed that $\mathrm{Nrf2}^{-1-}$ mice are more susceptible to develop CS-induced COPD than WT mice.

After treatment with AITC or NAC in the WT model mice, the pulmonary function index was higher than that in WT model group ( $\mathrm{p}<0.05)$, and the incomplete lung alveolar architecture and infiltration of inflammatory cells were also ameliorated. However, AITC could not significantly improve all lung function indexes of $\mathrm{Nrf}^{-/}$model mice, and the effect of reversing the pathological process of lung tissue was not as significant as that in the WT AITC group, suggesting that Nrf2 is an indispensable part of AITC in improving lung function in mice with COPD.

\section{Nrf2 gene knockout can impair the efficacy of AITC- induced MRP1 expression}

Our previous study revealed that AITC can reverse the expression of MRP1 in lung tissue of rats with COPD, and this change could improve the deteriorating condition of lung function. To investigate whether Nrf2 gene knockout had an effect on AITC mediated up-regulation of MRP1 expression, immunohistochemistry and western blotting were used. As shown in the immunohistochemistry results represented in Fig. 2, compared with that of the WT control group, the relative optical density of MRP1 was significantly reduced in the $\mathrm{Nrf}^{-/}$control group $(\mathrm{p}<0.05)$. This result indicates that the expression of MRP1 in mouse lung tissue is partially dependent on Nrf2, and the in vivo western blot experiment also verified this (Fig. 3). Compared with those in the WT control group, MRP1 and Nrf2 expression levels were lower in the WT model group (Fig. 4). In addition, the in vitro results showed that MRP1, Nrf2, and HO-1 (the target gene of Nrf2) also exhibited different degrees of reduced expression following different times of CSE treatment (Fig. 5).

Compared with that of the WT model group, the protein expression of MRP1, Nrf2 and HO-1 increased significantly in the WT AITC group $(\mathrm{p}<0.05)$. In vitro Western blotting showed that AITC significantly up-regulated $(\mathrm{p}<0.05)$ the expression of MRP1, Nrf2, and HO-1 in 16HBE cells (Fig. 6), while AITC pretreatment could obviously attenuate the decline in MRP1, Nrf2 and HO-1 protein expression induced by incubation with CSE. However, the in vivo results shown in Fig. 4 indicated that the effect of AITC on reversing MRP1 expression was significantly

Table 1. Comparison of mouse pulmonary function between the different groups

\begin{tabular}{|c|c|c|c|c|c|}
\hline Group & FEV0.3/FVC\% & FEV0.1 & PEF & FEF25-75 & Cdyn \\
\hline WT control group & $0.920 \pm 0.036$ & $0.819 \pm 0.035$ & $3.984 \pm 1.057$ & $7.682 \pm 0.310$ & $0.335 \pm 0.090$ \\
\hline WT model group & $0.686 \pm 0.188^{*}$ & $0.712 \pm 0.102^{\#}$ & $2.605 \pm 0.729^{\sharp}$ & $6.812 \pm 0.523^{\#}$ & $0.225 \pm 0.137^{\sharp}$ \\
\hline WT AITC group & $0.816 \pm 0.160^{\triangle}$ & $0.767 \pm 0.065^{\triangle}$ & $3.032 \pm 0.961^{\triangle}$ & $7.232 \pm 0.453^{\triangle}$ & $0.257 \pm 0.167^{\triangle}$ \\
\hline WT NAC group & $0.857 \pm 0.161^{\triangle}$ & $0.803 \pm 0.037^{\triangle}$ & $3.519 \pm 0.964^{\triangle}$ & $7.441 \pm 0.216^{\triangle}$ & $0.278 \pm 0.225^{\triangle}$ \\
\hline $\mathrm{Nrf}^{-/-}$control group & $0.931 \pm 0.049$ & $0.805 \pm 0.028$ & $3.24 \pm 1.148$ & $7.962 \pm 0.252$ & $0.324 \pm 0.016$ \\
\hline $\mathrm{Nrf}^{-/-}$model group & $0.625 \pm 0.242^{\nabla *}$ & $0.634 \pm 0.048^{\nabla *}$ & $1.886 \pm 0.822^{\nabla *}$ & $6.204 \pm 0.311^{\nabla *}$ & $0.166 \pm 0.015^{\nabla *}$ \\
\hline $\mathrm{Nrf}^{-/-}$AITC group & $0.696 \pm 0.321^{*}$ & $0.645 \pm 0.096$ & $1.903 \pm 1.302$ & $6.650 \pm 0.204^{*}$ & $0.169 \pm 0.102$ \\
\hline $\mathrm{Nrf2}^{-/}$NAC group & $0.704 \pm 0.146^{*}$ & $0.680 \pm 0.054^{*}$ & $2.355 \pm 0.883^{*}$ & $7.052 \pm 0.344^{*}$ & $0.213 \pm 0.156^{*}$ \\
\hline
\end{tabular}

Data are presented as the mean \pm standard deviation $(n=6)$. FEV, forced expiratory volume; FVC, forced vital capacity; PEF, peak expiratory flow; FEF, forced expiratory flow; Cdyn, Cldyn; WT, wild type; AITC, allyl isothiocyanate; NAC, N-acetylcysteine; Nrf2, nuclear factor erythroid 2-related factor $2 .{ }^{\sharp} \mathrm{p}<0.05 \mathrm{vs}$. WT control group, $\triangle_{\mathrm{p}}<0.05 \mathrm{vs}$. WT model group, $\nabla_{\mathrm{p}}<0.05 \mathrm{vs}$. Nrf2 ${ }^{-/-}$control group, ${ }^{*} \mathrm{p}<0.05$ vs. Nrf2 ${ }^{--}$model group, ${ }^{*} \mathrm{p}<0.05$ vs. WT model group. 
A WT ctrl group

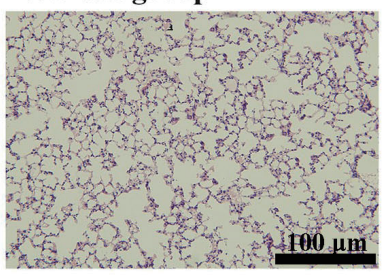

WT AITC group

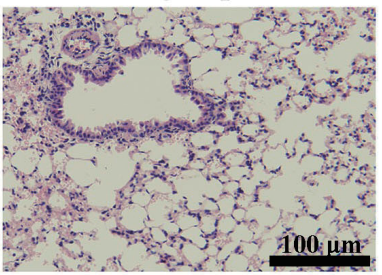

WT model group

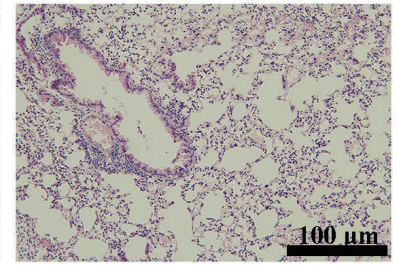

WT NAC group

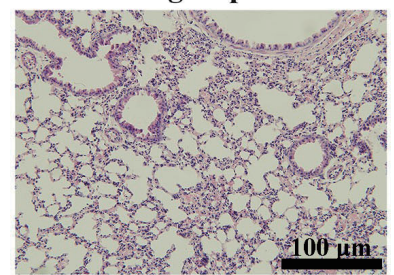

$\mathrm{Nrf2}^{-/}$ctrl group

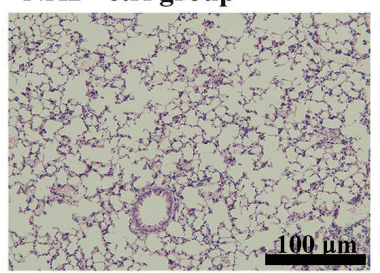

$\mathrm{Nrf2}^{--}$AITC group

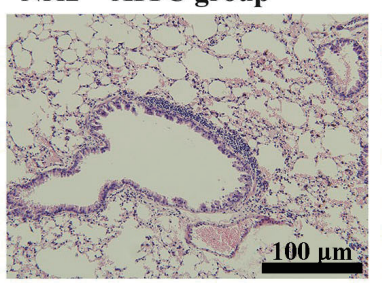

$\mathrm{Nrf2}^{-/}$model group

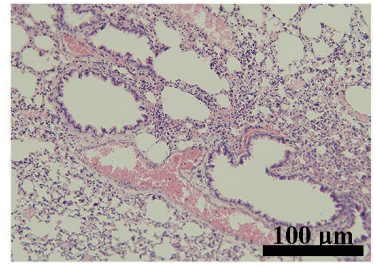

$\mathrm{Nrf}^{-/}$NAC group

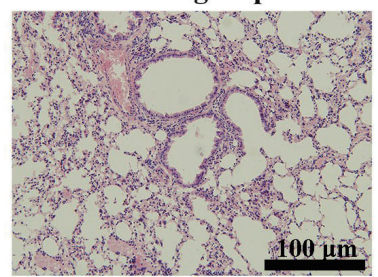

B

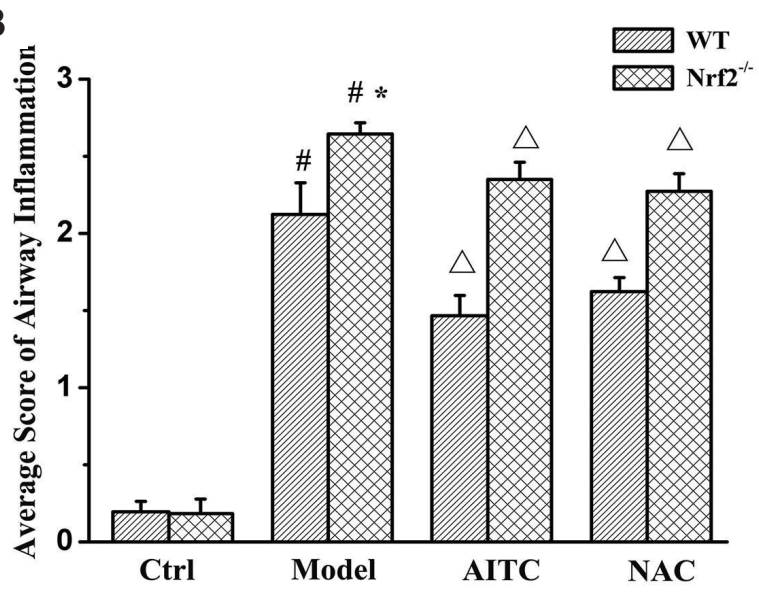

C

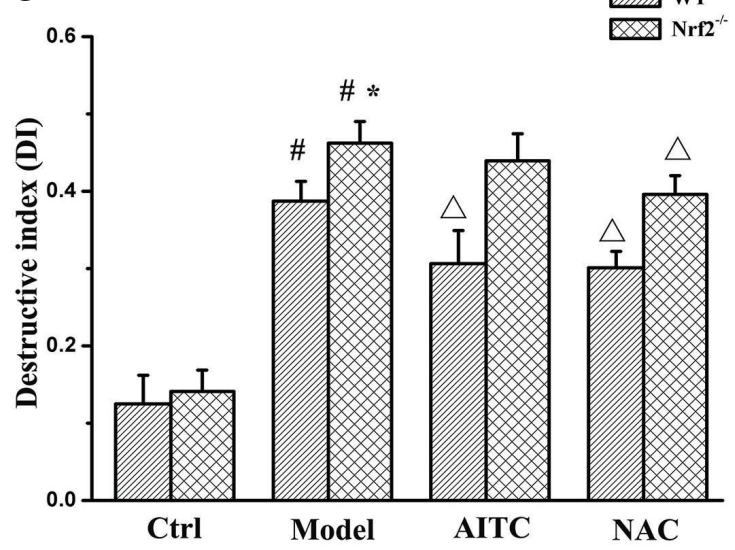

Fig. 1. Pathological evaluation of lung tissue. (A) Changes in lung histopathology observed following H\&E staining. (B) Average score of airway inflammation. ${ }^{*} p<0.05$ vs. control group, ${ }^{\Delta} p<0.05$ vs. model group, ${ }^{*} p<0.05$ vs. WT model group $(n=3)$. (C) Destructive index of alveoli, ${ }^{*} p<0.05$ vs. control group, ${ }^{*} p<0.05$ vs. model group, ${ }^{\Delta} p<0.05$ vs. WT model group $(n=3)$. WT, wild type; AITC, allyl isothiocyanate; NAC, N-acetylcysteine; Nrf2, nuclear factor erythroid 2-related factor 2.

impaired in $\mathrm{Nrf2}^{-/}$mice (1.20-fold, relative expression of MRP1 protein in the AITC group / relative expression of MRP1 protein in the model group as compared with WT mice [1.65-fold]). These findings demonstrate that the ability of AITC to regulate the expression of MRP1 is closely associated with Nrf2.

\section{AITC has a positive effect on the expression of the Nrf2 positive regulator DJ-1}

It has been reported that Nrf2 stability and transcriptional activity can be enhanced by DJ-1. In this study, a remarkable reduction in DJ-1 protein expression was observed in WT and Nrf2 1- model mice compared with WT and $\mathrm{Nrf2}^{-1}$ control groups, respectively (Fig. 4). After administration of AITC, the expression of DJ-1 was significantly higher than that in the WT and Nrf2 ${ }^{-1}$ model groups $(\mathrm{p}<0.05)$. The in vitro results indicated that DJ-1, like Nrf2, MRP1, and HO-1, showed a time-dependent reduction upon exposure to CSE $(\mathrm{p}<0.05)$. Pretreatment with AITC could reduce the CSE-induced degradation of DJ-1 protein $(\mathrm{p}<0.05)$ (Figs. 5 and 6). These data suggest that AITC also has a positive effect on the expression of the Nrf2 positive regulator DJ-1.

\section{Silencing the DJ-1 gene accelerates CSE-mediated protein degradation}

Prior to incubation with CSE, the DJ-1 gene was silenced by siRNA to detect the effect of DJ-1 on CSE-mediated protein degradation. As shown in Fig. 7, DJ-1 siRNA significantly reduced the mRNA and protein expression of DJ-1 compared with control siRNA group $(\mathrm{p}<0.05)$. There was no significant change in the expression of Nrf2, HO-1 or MRP1 in the siRNA DJ-1 group compared with that of the siRNA control group. Following 24-h CSE stimulation, the expressions levels of Nrf2, HO-1, and MRP1 were significantly decreased in both groups $(\mathrm{p}<0.05)$, and the expression levels in DJ-1 siRNA-transfected cells were lower than those in control siRNA-treated cells $(\mathrm{p}<0.05)$. This result illus- 


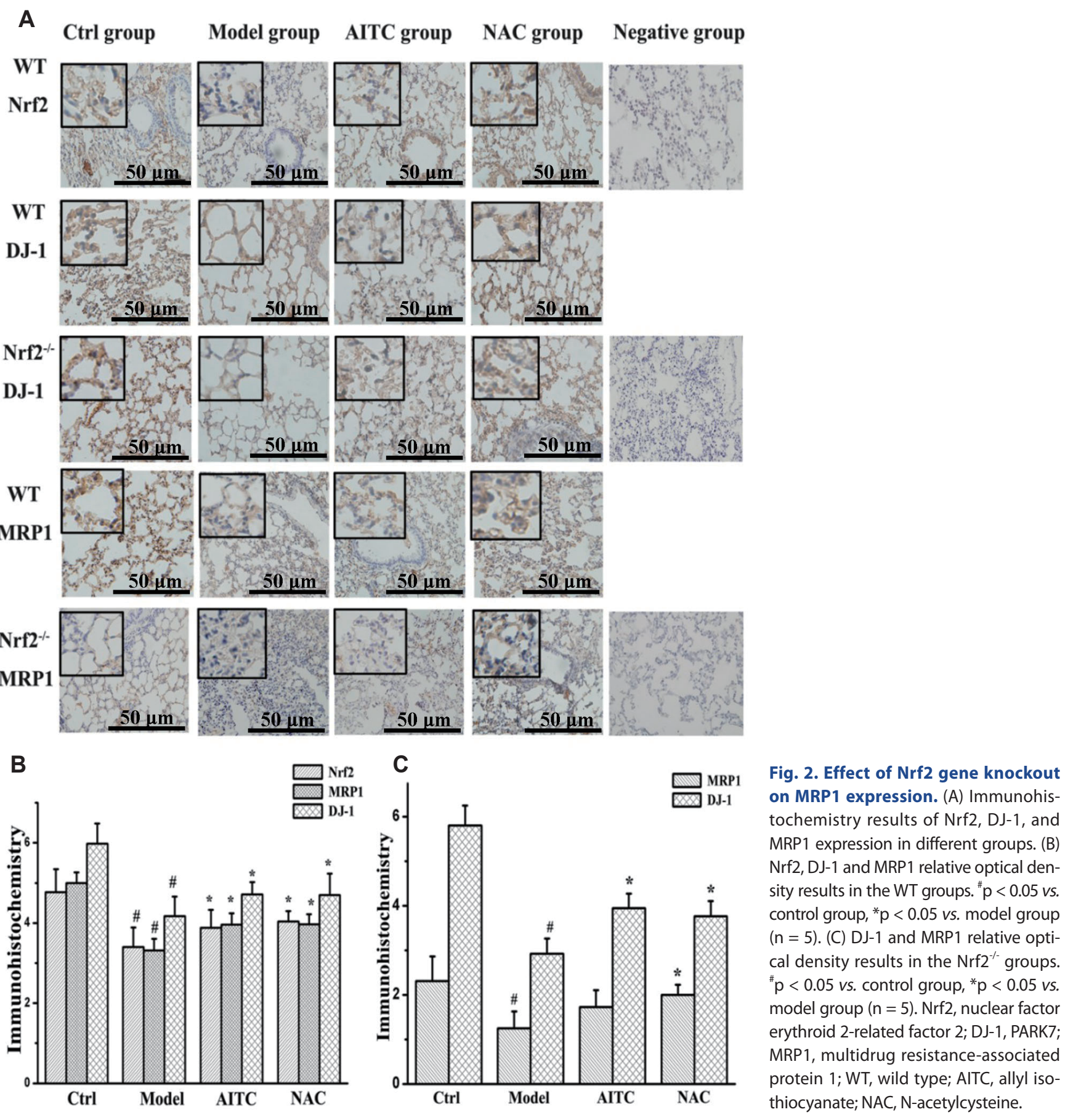

trates that the expression level of DJ-1 controls the expression of Nrf2, HO-1, and MRP1 in 16HBE cells stimulated by CSE.

\section{AITC may upregulate the expression the of MRP1 via activating the DJ-1/Nrf2 axis}

To further investigate the effect of DJ-1 on MRP1 and AITCinduced Nrf2 and MRP1 expression, 16HBE cells were transfected with DJ-1 siRNA before AITC treatment. After incubation with AITC (Fig. 8), a significant induction of DJ-1, Nrf2, HO-
1 , and MRP1 at the protein and mRNA level was observed in control siRNA-treated 16HBE cells ( $\mathrm{p}<0.05$ ), while DJ-1 siRNAtransfected cells showed an impaired ability to increase that $(\mathrm{p}$ $<0.05$ ). These results confirmed previous findings that DJ-1 facilitates the stability and transcriptional activity of Nrf2. Besides, the DJ-1 level controls the Nrf2 and MRP1 expression induced by AITC.

Overall, these results illustrate that AITC-induced MRP1 expression was attenuated following Nrf2 or DJ-1 knockout, confirming that both DJ-1 and Nrf2 are required for AITC-mediated 

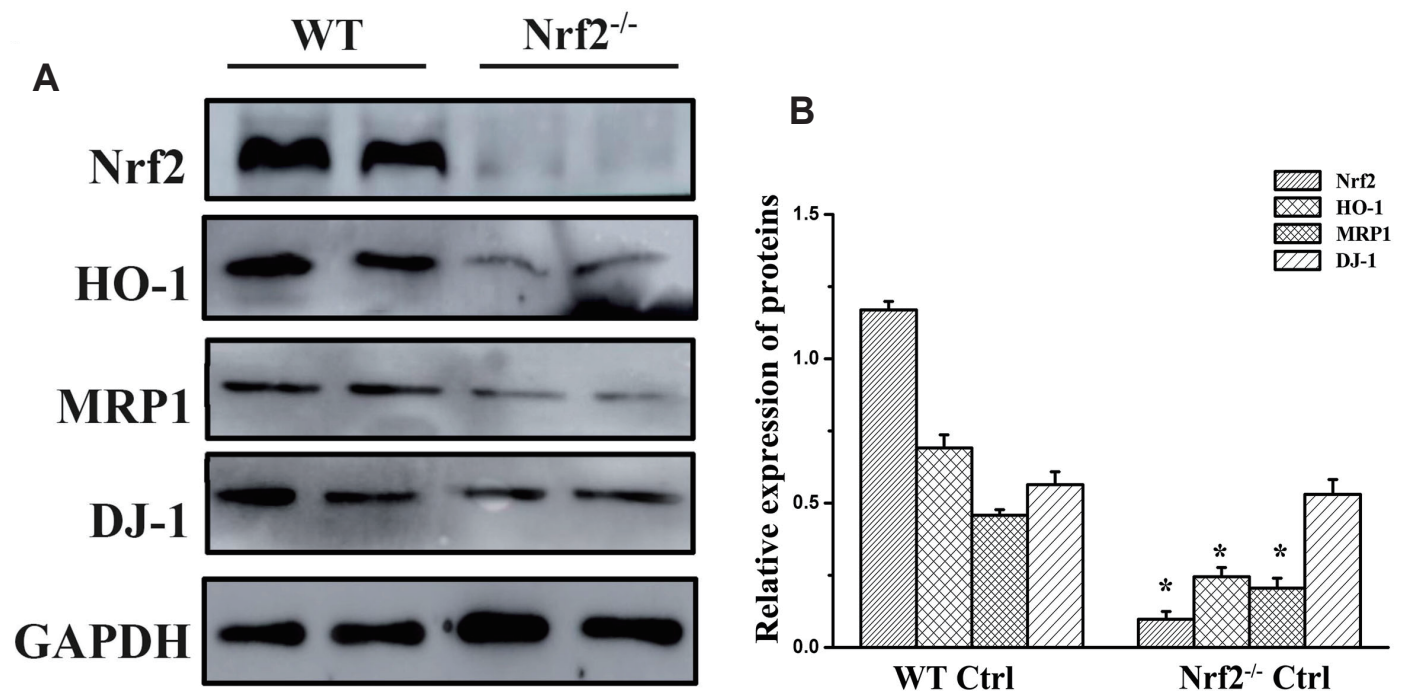

Fig. 3. Protein expression in the different groups. (A) Western blot results of Nrf2, DJ-1, MRP1, and HO-1 expression in the WT and Nrf2 ${ }^{-/}$control groups. GAPDH was used as the internal reference. (B) Quantitative analysis of the results of protein expression for each group. Nrf2, nuclear factor erythroid 2-related factor 2; DJ-1, PARK7; MRP1, multidrug resistance-associated protein 1; HO-1, heme oxygenase-1; WT, wild type. *p $<0.05$ vs. WT control group $(n=5)$.
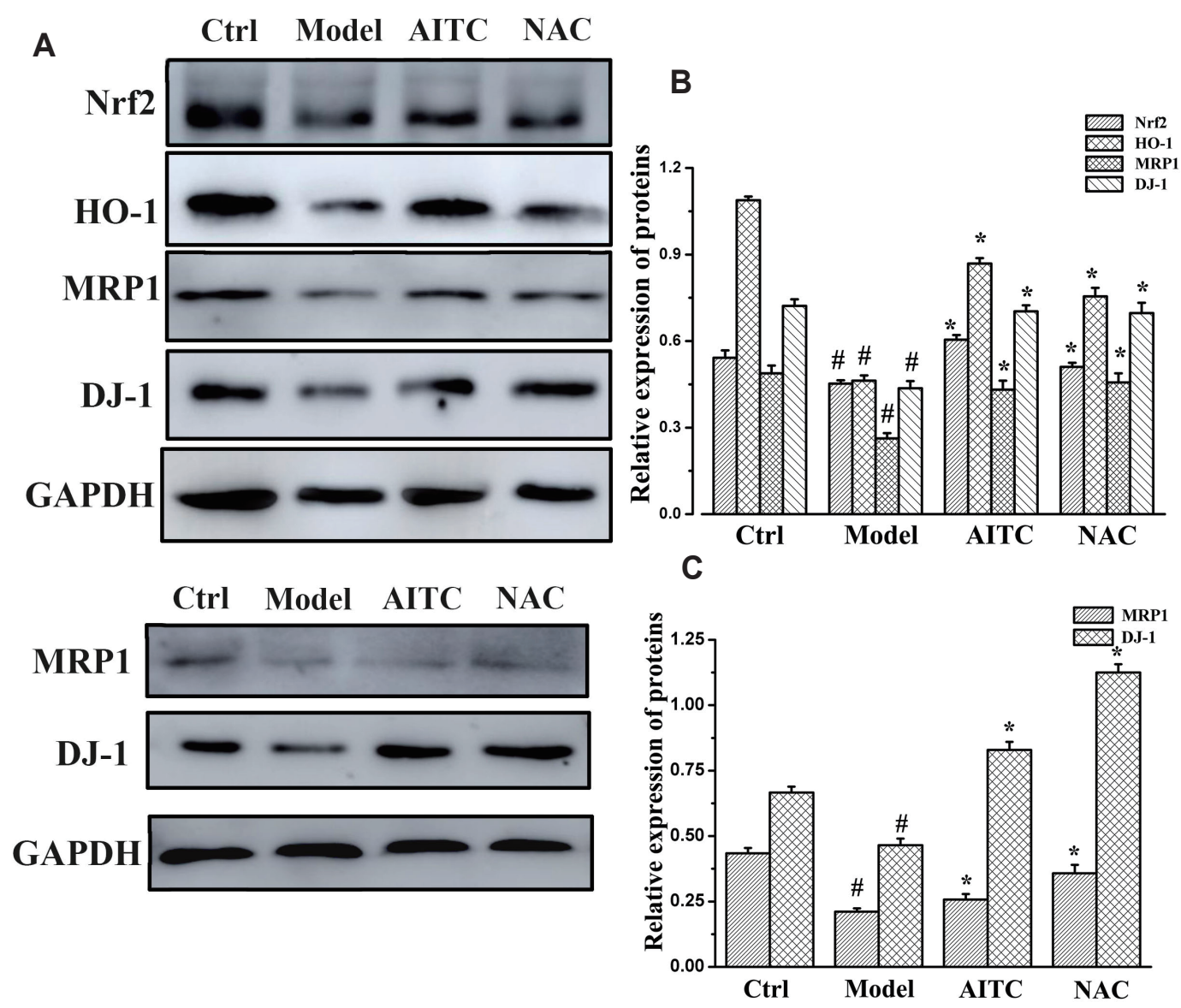

Fig. 4. Effect of AITC on MRP1 expression. (A) Western blot results of Nrf2, DJ-1, MRP1, and HO-1 expression in different groups. GAPDH was used as the internal reference. (B) Quantitative analysis of the results of protein expression in the WT groups. ${ }^{*} p<0.05 v s$. control group, ${ }^{*} p<0.05$ vs. model group $(n=5)$. (C) Quantitative analysis of the results of protein expression in the Nrf2 ${ }^{-1}$ groups. ${ }^{*} p<0.05$ vs. control group, ${ }^{*} p<0.05$ vs. model group $(n=5)$. Nrf2, nuclear factor erythroid 2-related factor 2; DJ-1, PARK7; MRP1, multidrug resistance-associated protein 1; HO-1, heme oxygenase-1; WT, wild type; AITC, allyl isothiocyanate; NAC, N-acetylcysteine. 

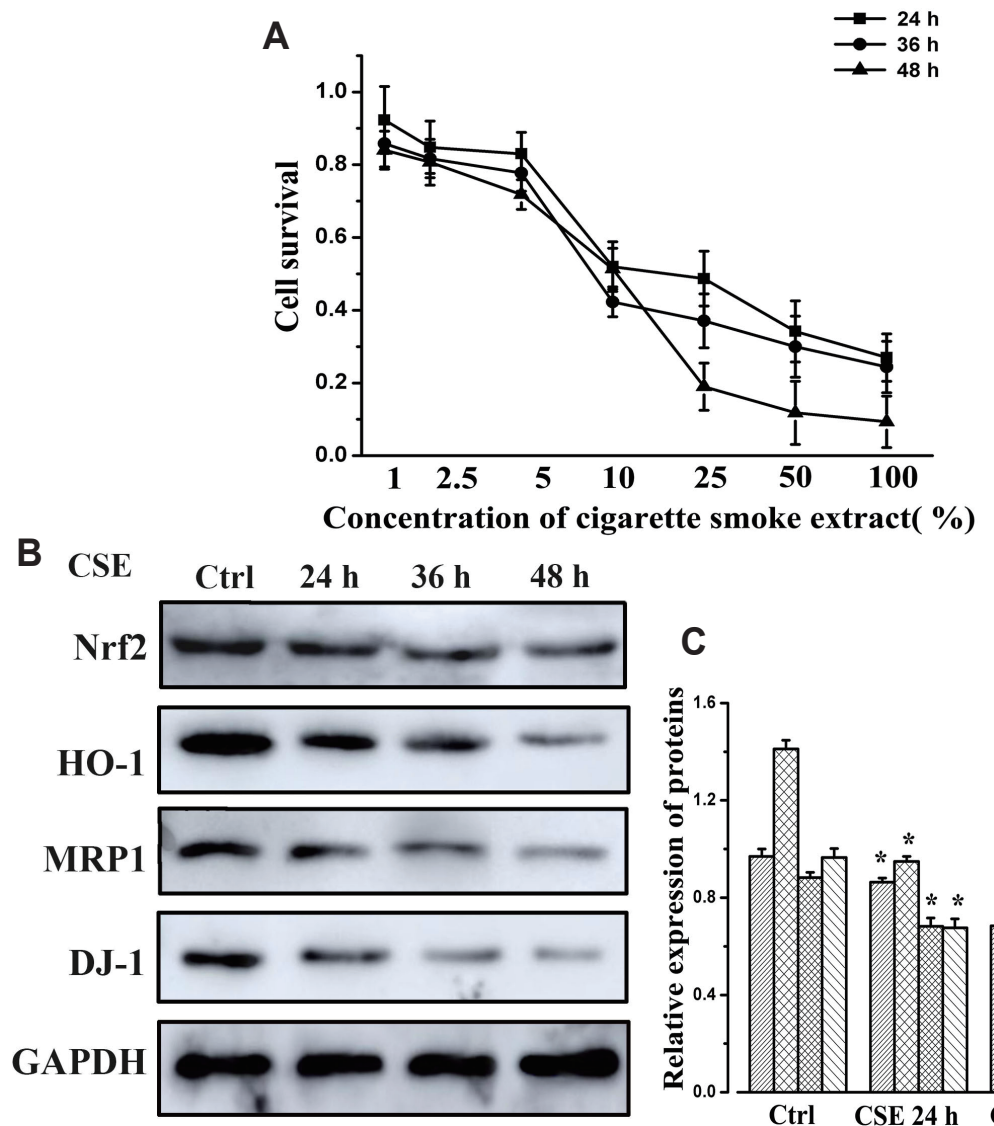

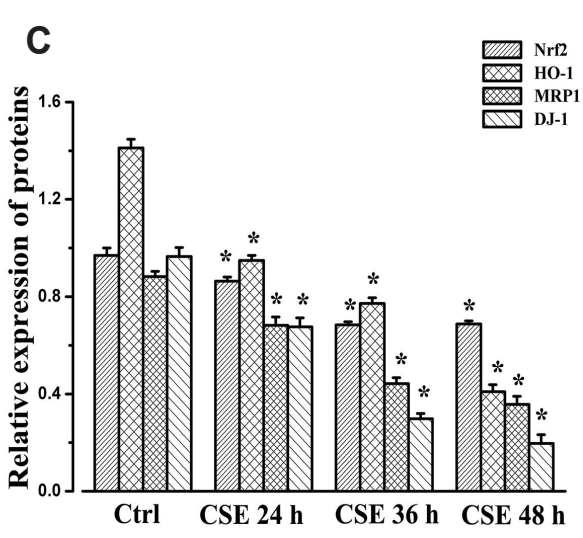

Fig. 5. Protein expression in $16 \mathrm{HBE}$ cells following CSE treatment. (A) MTT assay was used to determine the cellular toxicity of CSE in 16HBE cells. (B) Protein expression of Nrf2, DJ-1, MRP1, and HO-1 in 16HBE cells following treatment for different times with CSE. GAPDH was used as the internal reference. (C) Quantitative analysis of the results of protein expression in each group. CSE, cigarette smoke extract; 16HBE, human bronchial epithelial; Nrf2, nuclear factor erythroid 2-related factor 2; DJ-1, PARK7; MRP1, multidrug resistance-associated protein 1 ; HO-1, heme oxygenase-1. ${ }^{*} \mathrm{p}<0.05$ vs. control group $(n=5)$. protection. AITC may upregulate the expression of MRP1 by activating the DJ-1/Nrf2 axis.

\section{DISCUSSION}

It is well known that MRP1 is able to give a variety of cancer cells the ability to exhibit multi-drug resistance, but a recent study reported that it can protect organisms from foreign object damage by pumping cysteinyl leukotrienes $\mathrm{C} 4$ as well as numerous endogenous and exogenous organic anions out of cells. At the same time, it can also regulate different forms of GSH (oxidized or reduced), which play an integral part in OS [3,22-24]. Our previous study revealed that the decline in lung function and pathological changes in lung tissue in rats with COPD are closely associated with the downregulation of MRP1 protein expression [5]. Moreover, AITC, the active ingredient extracted from white mustard, can significantly increase the expression of MRP1 in $16 \mathrm{HBE}$ cells [16]. However, the exact mechanism of this action has not been fully elucidated to date.

A previous study reported that AITC can induce the expression of cytoprotective factors and antioxidant proteins by activating the Nrf2-ARE signaling pathway [10]. Besides, a growing body of research has indicated that the protein expression of MRP1 is involved in the transmission of Nrf2 signaling. For example, Yao et al. [25] reported that chaetominine can reduce MRP1- mediated drug resistance by inhibiting the PI3K/Akt/Nrf2 signaling pathway. Overexpression of Nrf2 upregulates MRPs expression in pancreatic ductal adenocarcinoma cells [26]. Using gene chip technology to analyze the small intestine of $\mathrm{Nrf}_{2}^{-/}$mice, it was found that Nrf2 is critical for the expression of MRP1 [27]. Therefore, it was hypothesized that AITC-induced MRP1 protein expression may be associated with the Nrf2 signaling pathway.

Data from animal models showed that, compared with that of the WT control group, the MRP1 and Nrf2 expression in the WT model group was significantly reduced, and the above trend was significantly improved after administration of AITC. Compared with that of the WT control group, MRP1 expression was markedly suppressed in the $\mathrm{Nrf} 2^{-/}$control group, which is in agreement with previous findings that MRP1 expression depends partly on Nrf2. It was observed that FEV0.3/FVC\%, PEF, PEF25-75 and Cdyn, which are relevant to pulmonary function, were significantly decreased in mice of the WT and $\mathrm{Nrf}^{-/}$model groups. In addition, compared with those of the WT model group, the above indexes were more significantly decreased in the $\mathrm{Nrf} 2^{-{ }^{-}}$model group. In the COPD group, there a large number of inflammatory cells and alveolar structural damage were observed. These changes were consistent with the pathological changes in rats with COPD. Pulmonary function and H\&E pathology showed that $\mathrm{Nrf2}^{-/}$mice were more likely to develop CS-induced COPD compared with WT mice. Moreover, the effect of AITC on upregulating MRP1 expression was significantly impaired in $\mathrm{Nrf}^{-/-}$mouse 
A

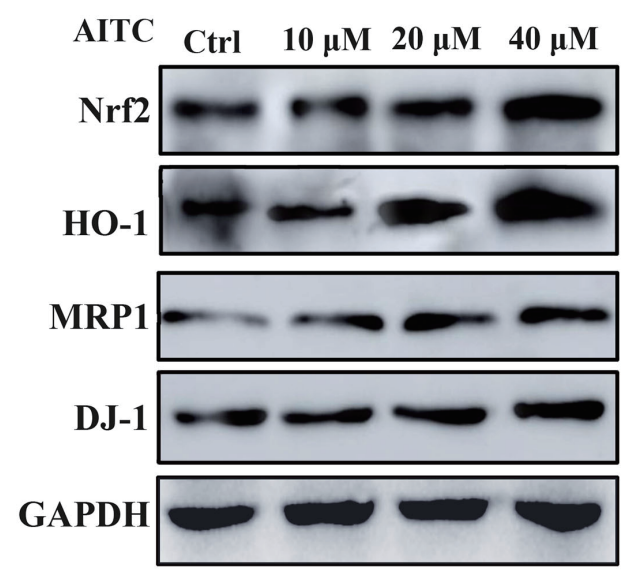

C

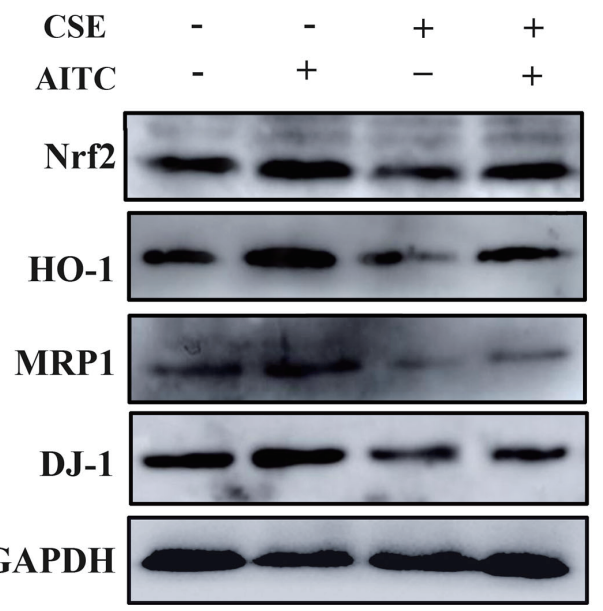

B

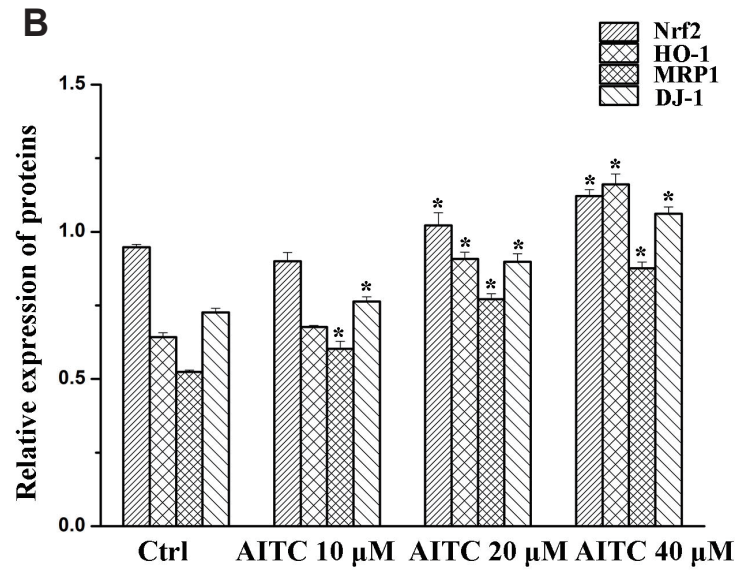

D

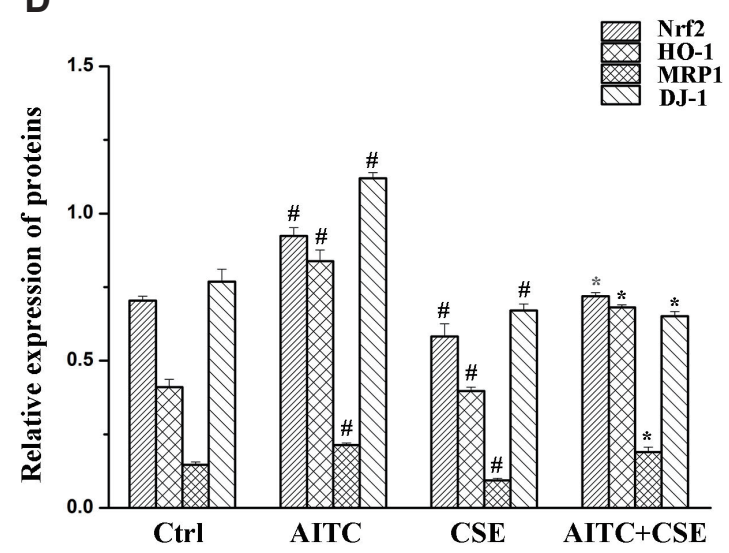

Fig. 6. Protein expression in 16HBE cells following treatment with AITC and CSE. (A) Protein expression of Nrf2, DJ-1, MRP1, and HO-1 in 16HBE cells following treatment with different concentrations of AITC. (B) Quantitative analysis of the results of protein expression in each group. * $p<0.05$ vs. control CSE group $(n=5)$. (C) Protein expression of Nrf2, DJ-1, MRP1, and HO-1 in 16HBE cells following treatment with AITC and CSE. GAPDH was used as the internal reference. (D) Quantitative analysis of the results of protein expression in each group. ${ }^{*} \mathrm{p}<0.05$ vs. control group, ${ }^{*} \mathrm{p}<0.05$ vs. CSE group $(n=5)$. 16HBE, human bronchial epithelial; Nrf2, nuclear factor erythroid 2-related factor 2; DJ-1, PARK7; MRP1, multidrug resistance-associated protein 1; HO-1, heme oxygenase-1; AITC, allyl isothiocyanate; CSE, cigarette smoke extract.

lung tissue. This result validated that Nrf2 participates in AITCinduced MRP1 expression.

Subsequent studies revealed that the expression of the Nrf2 positive regulator DJ-1 was also significantly reduced in lung tissue of COPD model mice. In agreement with the finding of Nrf2 and MRP1, DJ-1 protein showed a time-dependent reduction after incubation with CSE in vitro. Besides, in vivo and in vitro experiments confirmed that AITC also has a positive regulatory effect on DJ-1 expression. DJ-1 is a multifunctional protein, which is involved in various biological functions such as regulation of transcription of molecular chaperone activity and mitochondrial function [28]. In various studies, DJ-1 exhibited antioxidant properties and regulates Nrf2-dependent signaling activation [29-32]. A previous study demonstrated that inhibition of DJ-1 expression in mouse kidney decreased the expression and activity of Nrf2, which led to increased OS and elevated systolic blood pressure [33]. Moreover, Saidu et al. [34] found that high concentrations of dimethyl fumarate $(>25 \mu \mathrm{M})$ can reduce the expression of Nrf2 and its downstream antioxidant genes in several cancer cell lines by increasing the degradation of DJ-1 protein. Based on these findings, it was hypothesized that AITC upregulates Nrf2mediated MRP1 expression, and CSE induces the degradation of MRP1 protein, which may be associated with the DJ-1 expression level.

Next, the present study detected the expression of MRP1, Nrf2, and HO-1 in 16HBE cells after incubation with DJ-1 siRNA/Lipofectamine 2000 complex and AITC or CSE diluent to evaluate the association between DJ-1 and Nrf2-mediated MRP1. DJ-1 siRNA did not significantly affect the expression of Nrf2 or MRP1 in $16 \mathrm{HBE}$ cells under normal conditions. Following CSE stimulation, protein degradation of Nrf2 and MRP1 was significantly increased in the siRNA control and siRNA DJ-1 groups, and this was more notable in the siRNA DJ-1 group. This result suggests that the expression level of DJ-1 controls the expression of Nrf2 

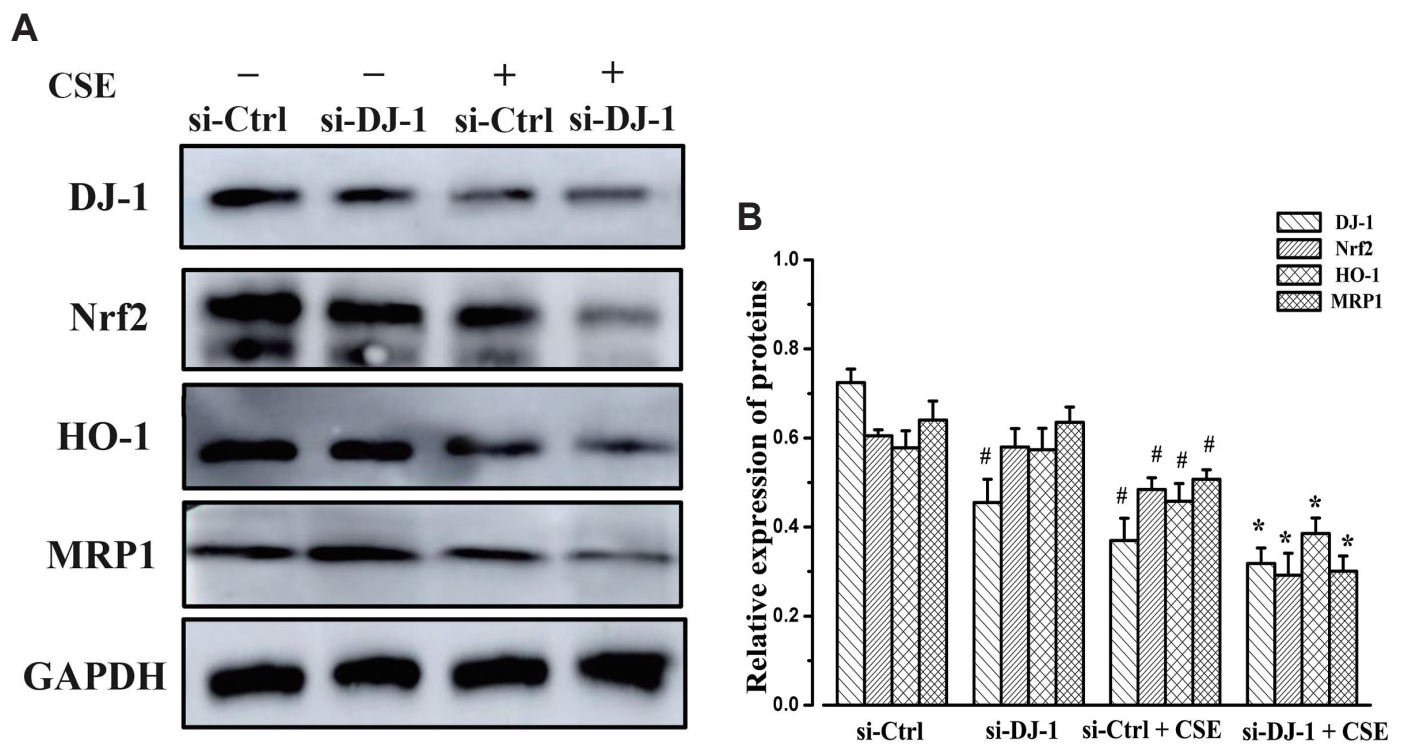

Fig. 7. Protein expression in $16 \mathrm{HBE}$ cells stimulated by CSE. (A) Protein expression of Nrf2, DJ-1, MRP1, and HO-1 in 16HBE cells following treatment with DJ-1siRNA/Lipofectamine 2000 complex and CSE. (B) Quantitative analysis of the results of protein expression in each group. 16HBE, human bronchial epithelial; Nrf2, nuclear factor erythroid 2-related factor 2; DJ-1, PARK7; MRP1, multidrug resistance-associated protein 1; HO-1, heme oxygenase-1; CSE, cigarette smoke extract. ${ }^{*} \mathrm{p}<0.05$ vs. control group, ${ }^{*} \mathrm{p}<0.05$ vs. si-Ctrl+CSE group $(\mathrm{n}=5)$.
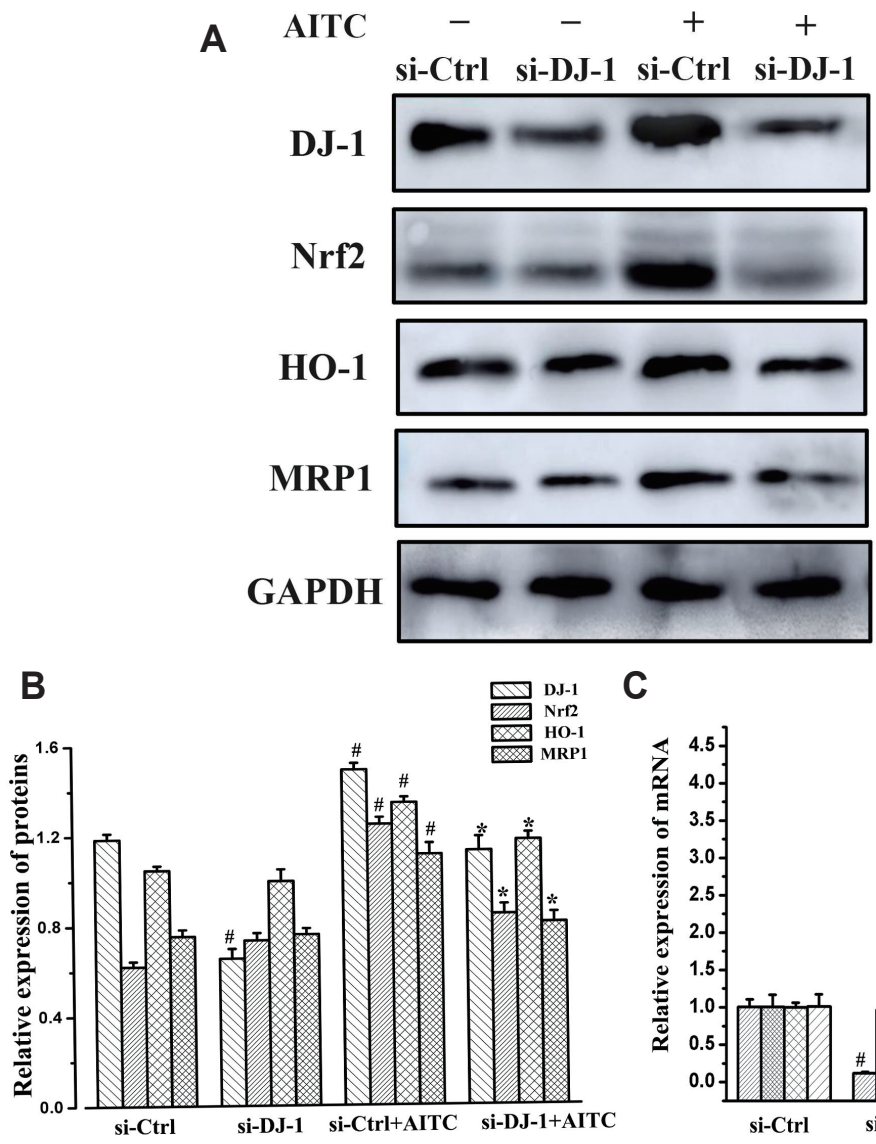

C

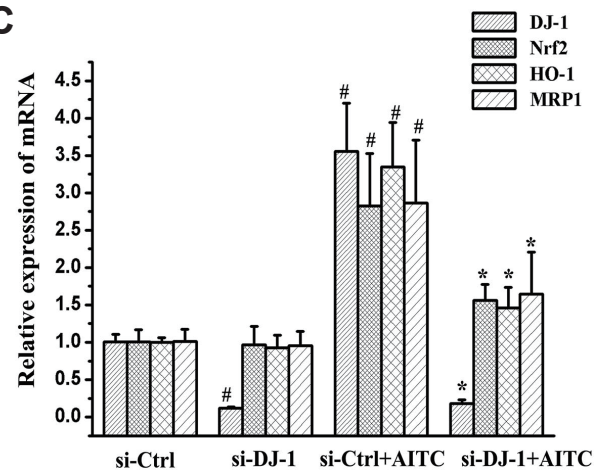

Fig. 8. Effect of DJ-1 on MRP1 and AITC-induced Nrf2 and MRP1 expression. (A) Protein expression of Nrf2, DJ-1, MRP1, and HO-1 in 16HBE cells following treatment with DJ-1siRNA/ Lipofectamine 2000 complex and AITC. (B) Quantitative analysis of the results of protein expression in each group. $" \mathrm{p}<$ 0.05 vs. control group, ${ }^{*} p<0.05$ vs. siCtrl+AITC group $(n=5)$. (C) mRNA expression of Nrf2, DJ-1, MRP1 and HO-1 in $16 \mathrm{HBE}$ cells following treatment with DJ1siRNA/ Lipofectamine 2000 complex and AITC. GAPDH was used as the internal reference. ${ }^{*} \mathrm{p}<0.05$ vs. control group, ${ }^{*} p<0.05$ vs. si-Ctrl+AITC group $(n=6)$. $16 \mathrm{HBE}$, human bronchial epithelial; Nrf2, nuclear factor erythroid 2-related factor 2; DJ-1, PARK7; MRP1, multidrug resistance-associated protein 1; HO-1, heme oxygenase-1; AITC, allyl isothiocyanate. and Nrf2-mediated MRP1 in 16HBE cells stimulated by CSE. After incubation with AITC, Nrf2 and MRP1 expression increased significantly in control siRNA-treated $16 \mathrm{HBE}$ cells, while DJ-1
siRNA-transfected cells exhibited a repressed effect to increase that. This suggests that the absence of DJ-1 affects AITC-induced Nrf2 expression and transcription as well as Nrf2-mediated 


\section{MRP1 expression.}

The present study firstly illustrated that the expression trends of DJ-1, Nrf2, and MRP1 were consistent after CS/CSE stimulation and AITC treatment. Next, it was found that DJ-1 could positively regulate the Nrf2-mediated antioxidant defense system against CS-induced OS in Alveolar type II cells [35]. Moreover, AITC-induced MRP1 expression and CS/CSE-mediated MRP1 protein degradation could be affected by DJ-1 and Nrf2. Taken together, these results can describe a novel mechanism by which AITC induces MRP1 expression by protecting against CS/CSEmediated DJ-1 protein degradation via activation of the DJ-1/Nrf2 axis. However, the antioxidant role of DJ-1 protein in COPD disease and the mechanism of AITC-induced DJ-1 expression still need further investigation. This study may provide new targets and topics for COPD research.

\section{ACKNOWLEDGEMENTS}

This work was supported by grants from the National Natural Science Foundation of China (no. 81473536).

\section{CONFLICTS OF INTEREST}

The authors declare no conflicts of interest.

\section{REFERENCES}

1. Yang SR, Chida AS, Bauter MR, Shafiq N, Seweryniak K, Maggirwar SB, Kilty I, Rahman I. Cigarette smoke induces proinflammatory cytokine release by activation of NF-kappaB and posttranslational modifications of histone deacetylase in macrophages. Am J Physiol Lung Cell Mol Physiol. 2006;291:L46-L57.

2. Lapperre TS, Postma DS, Gosman MM, Snoeck-Stroband JB, ten Hacken NH, Hiemstra PS, Timens W, Sterk PJ, Mauad T. Relation between duration of smoking cessation and bronchial inflammation in COPD. Thorax. 2006;61:115-121.

3. Cole SP. Targeting multidrug resistance protein 1 (MRP1, ABCC1): past, present, and future. Annu Rev Pharmacol Toxicol. 2014;54:95117.

4. van der Deen M, Marks H, Willemse BW, Postma DS, Müller M, Smit EF, Scheffer GL, Scheper RJ, de Vries EG, Timens W. Diminished expression of multidrug resistance-associated protein 1 (MRP1) in bronchial epithelium of COPD patients. Virchows Arch. 2006;449:682-688.

5. Wang DL, Zhang X, Tao XH. Effects of huatan jiangqi capsule on the levels of multi-drug resistance-associated protein 1 in the bronchial epithelial cells of model rats with chronic obstructive pulmonary disease. Zhongguo Zhong Xi Yi Jie He Za Zhi. 2012;32:955-959.

6. van der Deen M, Homan S, Timmer-Bosscha H, Scheper RJ, Timens W, Postma DS, de Vries EG. Effect of COPD treatments on MRP1mediated transport in bronchial epithelial cells. Int J Chron $\mathrm{Ob}$ - struct Pulmon Dis. 2008;3:469-475.

7. Kushad MM, Brown AF, Kurilich AC, Juvik JA, Klein BP, Wallig MA, Jeffery EH. Variation of glucosinolates in vegetable crops of Brassica oleracea. J Agric Food Chem. 1999;47:1541-1548.

8. Munday R, Zhang Y, Fahey JW, Jobson HE, Munday CM, Li J, Stephenson KK. Evaluation of isothiocyanates as potent inducers of carcinogen-detoxifying enzymes in the urinary bladder: critical nature of in vivo bioassay. Nutr Cancer. 2006;54:223-231.

9. Ye L, Zhang Y. Total intracellular accumulation levels of dietary isothiocyanates determine their activity in elevation of cellular glutathione and induction of Phase 2 detoxification enzymes. Carcinogenesis. 2001;22:1987-1992.

10. McWalter GK, Higgins LG, McLellan LI, Henderson CJ, Song L, Thornalley PJ, Itoh K, Yamamoto M, Hayes JD. Transcription factor $\mathrm{Nrf2}$ is essential for induction of $\mathrm{NAD}(\mathrm{P}) \mathrm{H}$ :quinone oxidoreductase 1, glutathione S-transferases, and glutamate cysteine ligase by broccoli seeds and isothiocyanates. J Nutr. 2004;134(12 Suppl):3499S3506S.

11. Vomhof-Dekrey EE, Picklo MJ Sr. The Nrf2-antioxidant response element pathway: a target for regulating energy metabolism. J Nutr Biochem. 2012;23:1201-1206.

12. Boutten A, Goven D, Artaud-Macari E, Boczkowski J, Bonay M. NRF2 targeting: a promising therapeutic strategy in chronic obstructive pulmonary disease. Trends Mol Med. 2011;17:363-371.

13. Lee E, Yin Z, Sidoryk-Węgrzynowicz M, Jiang H, Aschner M. 15 -Deoxy- $\Delta 12,14$-prostaglandin $\mathrm{J}_{2}$ modulates manganese-induced activation of the NF- $\kappa \mathrm{B}, \mathrm{Nrf2}$, and PI3K pathways in astrocytes. Free Radic Biol Med. 2012;52:1067-1074.

14. Cuevas S, Yang Y, Konkalmatt P, Asico LD, Feranil J, Jones J, Villar VA, Armando I, Jose PA. Role of nuclear factor erythroid 2-related factor 2 in the oxidative stress-dependent hypertension associated with the depletion of DJ-1. Hypertension. 2015;65:1251-1257.

15. Udasin RG, Wen X, Bircsak KM, Aleksunes LM, Shakarjian MP, Kong AN, Heck DE, Laskin DL, Laskin JD. Nrf2 regulates the sensitivity of mouse keratinocytes to nitrogen mustard via multidrug resistance-associated protein 1 (Mrp1). Toxicol Sci. 2016;149:202-212.

16. Wang DL, Wang CY, Cao Y, Zhang X, Tao XH, Yang LL, Chen JP, Wang SS, Li ZG. Allyl isothiocyanate increases MRP1 function and expression in a human bronchial epithelial cell line. Oxid Med Cell Longev. 2014;2014:547379.

17. Wright JL, Churg A. Animal models of cigarette smoke-induced chronic obstructive pulmonary disease. Expert Rev Respir Med. 2010;4:723-734.

18. Cai S, Chen P, Zhang C, Chen JB, Wu J. Oral N-acetylcysteine attenuates pulmonary emphysema and alveolar septal cell apoptosis in smoking-induced COPD in rats. Respirology. 2009;14:354-359.

19. Cao Y. Study on the mechanism of allyl isothiocyanate in the treatment of COPD based on the expression of MRP1 [Master thesis]. Hefei: Anhui University of Chinese Medicine; 2013.

20. Gueders MM, Bertholet P, Perin F, Rocks N, Maree R, Botta V, Louis R, Foidart JM, Noel A, Evrard B, Cataldo DD. A novel formulation of inhaled doxycycline reduces allergen-induced inflammation, hyperresponsiveness and remodeling by matrix metalloproteinases and cytokines modulation in a mouse model of asthma. Biochem Pharmacol. 2008;75:514-526.

21. Livak KJ, Schmittgen TD. Analysis of relative gene expression data using real-time quantitative PCR and the $2^{-\Delta \Delta C_{\mathrm{T}}}$ method. Methods. 
2001;25:402-408.

22. Neuser J, Fraccarollo D, Wick M, Bauersachs J, Widder JD. Multidrug resistance associated protein-1 (MRP1) deficiency attenuates endothelial dysfunction in diabetes. J Diabetes Complications. 2016; 30:623-627.

23. Gordillo GM, Biswas A, Khanna S, Spieldenner JM, Pan X, Sen CK. Multidrug resistance-associated protein-1 (MRP-1)-dependent glutathione disulfide (GSSG) efflux as a critical survival factor for oxidant-enriched tumorigenic endothelial cells. J Biol Chem. 2016;291:10089-10103.

24. Deng J, Coy D, Zhang W, Sunkara M, Morris AJ, Wang C, Chaiswing L, St Clair D, Vore M, Jungsuwadee P. Elevated glutathione is not sufficient to protect against doxorubicin-induced nuclear damage in heart in multidrug resistance-associated protein 1 (Mrp1/ Abccl) null mice. J Pharmacol Exp Ther. 2015;355:272-279.

25. Yao J, Wei X, Lu Y. Chaetominine reduces MRP1-mediated drug resistance via inhibiting PI3K/Akt/Nrf2 signaling pathway in K562/Adr human leukemia cells. Biochem Biophys Res Commun. 2016;473:867-873.

26. Hong YB, Kang HJ, Kwon SY, Kim HJ, Kwon KY, Cho CH, Lee JM, Kallakury BV, Bae I. Nuclear factor (erythroid-derived 2)-like 2 regulates drug resistance in pancreatic cancer cells. Pancreas. 2010; 39:463-472.

27. Thimmulappa RK, Mai KH, Srisuma S, Kensler TW, Yamamoto M, Biswal S. Identification of Nrf2-regulated genes induced by the chemopreventive agent sulforaphane by oligonucleotide microarray. Cancer Res. 2002;62:5196-5203.

28. Raninga PV, Trapani GD, Tonissen KF. Cross talk between two antioxidant systems, thioredoxin and DJ-1: consequences for cancer.
Oncoscience. 2014;1:95-110.

29. Wilson MA. The role of cysteine oxidation in DJ-1 function and dysfunction. Antioxid Redox Signal. 2011;15:111-122.

30. Zhang XL, Yuan YH, Shao QH, Wang ZZ, Zhu CG, Shi JG, Ma KL, Yan X, Chen NH. DJ-1 regulating PI3K-Nrf2 signaling plays a significant role in bibenzyl compound 20C-mediated neuroprotection against rotenone-induced oxidative insult. Toxicol Lett. 2017;271:7483.

31. Vavougios G, Zarogiannis SG, Doskas T. The putative interplay between DJ-1/NRF2 and Dimethyl Fumarate: a potentially important pharmacological target. Mult Scler Relat Disord. 2018;21:88-91.

32. Li R, Wang S, Li T, Wu L, Fang Y, Feng Y, Zhang L, Chen J, Wang X. Salidroside protects dopaminergic neurons by preserving complex I activity via DJ-1/Nrf2-mediated antioxidant pathway. Parkinsons Dis. 2019;2019:6073496.

33. Srivastava S, Blower PJ, Aubdool AA, Hider RC, Mann GE, Siow RC. Cardioprotective effects of $\mathrm{Cu}^{(\mathrm{II})} \mathrm{ATSM}$ in human vascular smooth muscle cells and cardiomyocytes mediated by Nrf2 and DJ1. Sci Rep. 2016;6:7.

34. Saidu NE, Noé G, Cerles O, Cabel L, Kavian-Tessler N, Chouzenoux S, Bahuaud M, Chéreau C, Nicco C, Leroy K, Borghese B, Goldwasser F, Batteux F, Alexandre J. Dimethyl fumarate controls the NRF2/ DJ-1 axis in cancer cells: therapeutic applications. Mol Cancer Ther. 2017;16:529-539.

35. Bahmed K, Messier EM, Zhou W, Tuder RM, Freed CR, Chu HW, Kelsen SG, Bowler RP, Mason RJ, Kosmider B. DJ-1 modulates nuclear erythroid 2-related factor-2-mediated protection in human primary alveolar type II cells in smokers. Am J Respir Cell Mol Biol. 2016;55:439-449. 